\title{
ANATOMIA COMPARADA DE FOLHAS DE EICHHORNIA CRASSIPES
}

Thereza Grassiolli

Departamento de Biologia. Centro de Ciências Naturais e Exatas. UFSM. Santa Maria, RS.

\section{RESUMO}

Fez-se um estudo anatómico comparativo de folhas com pecío 10 longo e folhas com pecỉolo inflado de Eichhornia crassipes, desen volvida em condições naturais. O resultado mostrou que a diferença morfológica pecỉolo longo, pecỉolo inflado, está relacionada com o volume de espaços aeriferos. Fatores ambientais contribuem para esta variação.

\section{SUMMARY}

GRASSIOLLI,T., 1980. Anatomical comparison of leaves of Eichhornia crassipes. Ciēncia e Natura (2): 121-131.

A comparative anatomical study of leaves with long petiole and leaves with inflated petiole of Eichhornia crassipes, developed under normal conditions, was made. This study proved that the morpho logical differences between long petiole and inflated petiole is re lated to the volume of aeriferous spaces. Environmental factors con tribute to this variation.

INTRODUÇÃO

Eichhornia crassipes (Mart.) Solms - Laubach, conhecida vul garmente pelo nome de aguapē, pertence a famīlia Pontederiaceae que tem representantes em todas as regiões tropicais do mundo. No Bra sil, esta famīila constitui o maior volume da flora aquática (HOEHNE, 3).

CASTELLANOS \& KLEIN (1) descrevem Eichhornia crassipes co mo hidrófitas fixas ou nadantes. Neste ūitimo caso, apresentam folhas com peciolos curtos, inflados, quase esféricos e muito esponjosos. Quando fixos, os pecíolos são longos, chegando a medir mais de $30 \mathrm{~cm}$ de comprimento.

Neste trabalho, procurou-se comparar a estrutura de folhas de peciolo longo com folhas de peciolo inflado de Eichhornia crassi pes e relacionar aspectos morfolögicos com o ambiente, além de forne cer dados anatômicos que possam servir para pesquisas de fisioecolo gia e de taxionomia.

WEAVER \& CLEMENTS (9) ressaltam que $\bar{e}$ importante estudar não sō a estrutura e evolução de uma vegeteção mas, tambēm, como esta 
vegetação é afetada pelo ambiente.

MORRETES (7) lembra que um mesmo fenōmeno anatōmico pode ter origem em diferentes causas.

ESAU (2) dá ènfase à relação entre estrutura e função, mos trando ser indispensāvel o estudo histolōgico de uma planta para po der explicar seu comportamento e caracteristicas.

MATERIAL E METODOS

Para a realização do presente trabalho, foram observadas es pécimes nadantes e fixas de Eichhornia crassipes, nas condições natu rais.

Para a añilise anatômica da folha foram feitos cortes trans versais e paradērmicos, na região mediana do peciolo e da lāmina fo liar, à mão livre e com auxîlio do micrōtomo rotativo. Como fixado res foram usados FAA5O (JOHANSEN, 6) e älcool etīlico a 70\% (JENSEN, $5)$. Os cortes à mão livre, feitos a partir de material vivo, foram colocados em àlcool $70 \%$, durante 10 minutos, para expelir o ar. Des tes cortes foram feitas lâminas temporārias tendo sido usado, como meio de montagem, álcool a $70 \%$. O material cortado por micrótomo ro tativo, após a fixação, foi submetido à desidratação na sērie alcoó lica etîlica e à infiltração de parafina, seguida de inclusão(SASS, 8). Na coloração das lâminas permanentes foi usado o processo de du pla coloraçāo safranina -fast green (SASS, 8). Para identificaçāo da celulose utilizou-se cloreto de zinco iodado (JENSEN, 5). Paredes lignificadas foram identificadas pela floroglucina ācida (SASS, 8 ). Cuticula e paredes cutinizadas foram evidenciadas pelo sudan IV (JOHANSEN, 6). Cristais de oxalato de cálcio foram identificados pe los àcidos cloridrico e sulfürico (JOHANSEN, 6).

As observacões microscópicas e os desenhos foram feitos, predominantemente, a partir de lâminas temporärias; quando necessá rio, estas preparações foram comparadas com as permanentes. Na ela boração dos desenhos utilizou-se a cāmara clara e nas mesmas condi çoes óticas em que foram feitos os desenhos foi projetada a escala que os acompanha.

A determinação do volume ocupado pelos espaços aeríferos, nos pecïolos longo e inflado e na lâmina foliar, foi obtida pelo më todo estereológico da fração de pontos (IFJU, 4). As determinações histomêtricas são apresentadas nas Tabelas I e II.

RESULTADOS

Observou-se que os individuos fixos de Éichhornia crassi pes apresentam folhas com pecioio iongo. Os individuos nadantes, ae senvolvidos em local onde há ampla ärea superficial disponível em re 
TABELA I. VALORES DA DETERMINAÇAO HISTOMETRICA DAS FRAÇOES DE CELU LAS E ESPAÇOS NA LĀMINA FOLIAR DE EICHHORNIA CRASSIPES.

\begin{tabular}{|c|c|c|c|}
\hline Estrutura & $\begin{array}{l}\text { Determinação } \\
\text { histométrica }\end{array}$ & $\begin{array}{c}\text { Mēdia } \\
\%\end{array}$ & $\begin{array}{l}\text { Desvio } \\
\text { padrão }\end{array}$ \\
\hline Làmina de & $\begin{array}{l}\text { Fração de } \\
\text { cēlulas }\end{array}$ & 83,5 & 2,27 \\
\hline longo & $\begin{array}{l}\text { Fração de } \\
\text { espaços }\end{array}$ & 16,5 & 2,27 \\
\hline Lâmina de & $\begin{array}{l}\text { Fração de } \\
\text { células }\end{array}$ & 68,1 & 1,729 \\
\hline inflado & $\begin{array}{l}\text { Fração de } \\
\text { espaços }\end{array}$ & 31,9 & 1,729 \\
\hline
\end{tabular}

TABELA II. VALORES DA DETERMINAÇAO HISTOMETRICA DAS FRAÇOES DE CELL LAS E ESPAÇOS NO PECIOLO DE EICHHORNIA CRASSIPES.

\begin{tabular}{|c|c|c|c|}
\hline Estrutura & $\begin{array}{l}\text { Determinação } \\
\text { his tométrica }\end{array}$ & $\begin{array}{c}\text { Média } \\
\%\end{array}$ & $\begin{array}{l}\text { Desvio } \\
\text { padrão }\end{array}$ \\
\hline Pecíolo & $\begin{array}{l}\text { Fração de } \\
\text { células }\end{array}$ & 45,4 & 1,075 \\
\hline longo & $\begin{array}{l}\text { Fração de } \\
\text { espaços }\end{array}$ & 54,6 & 1,075 \\
\hline Peciolo & $\begin{array}{l}\text { Fração de } \\
\text { células }\end{array}$ & 21,0 & 1,247 \\
\hline inflado & $\begin{array}{l}\text { Fração de } \\
\text { espaços }\end{array}$ & 79,0 & 1,247 \\
\hline
\end{tabular}

lação ao número de espécimes, apresentam folhas com peciolo curto e inflado.

Individuos com folha de peciolo inflado, transportados pa ra local onde a ārea é reduzida, vão apresentando gradativamente fó lhas com peciolo alongado. Individuos com folhas de peciolo longo, transportados para local onde a ārea superficial disponivel ao seu crescimento é ampla, passam a apresentar, gradativamente, folhas com peciolo inflado.

\section{ESTRUTURA DA LÂMINA FOLIAR}

Comparando-se a estrutura da lâmina foliar da folha de pe cỉolo longo com a de pecīolo inflado, ao nível da região mediana, en controu-se poucas diferenças (Figuras 1 e 2 ). 

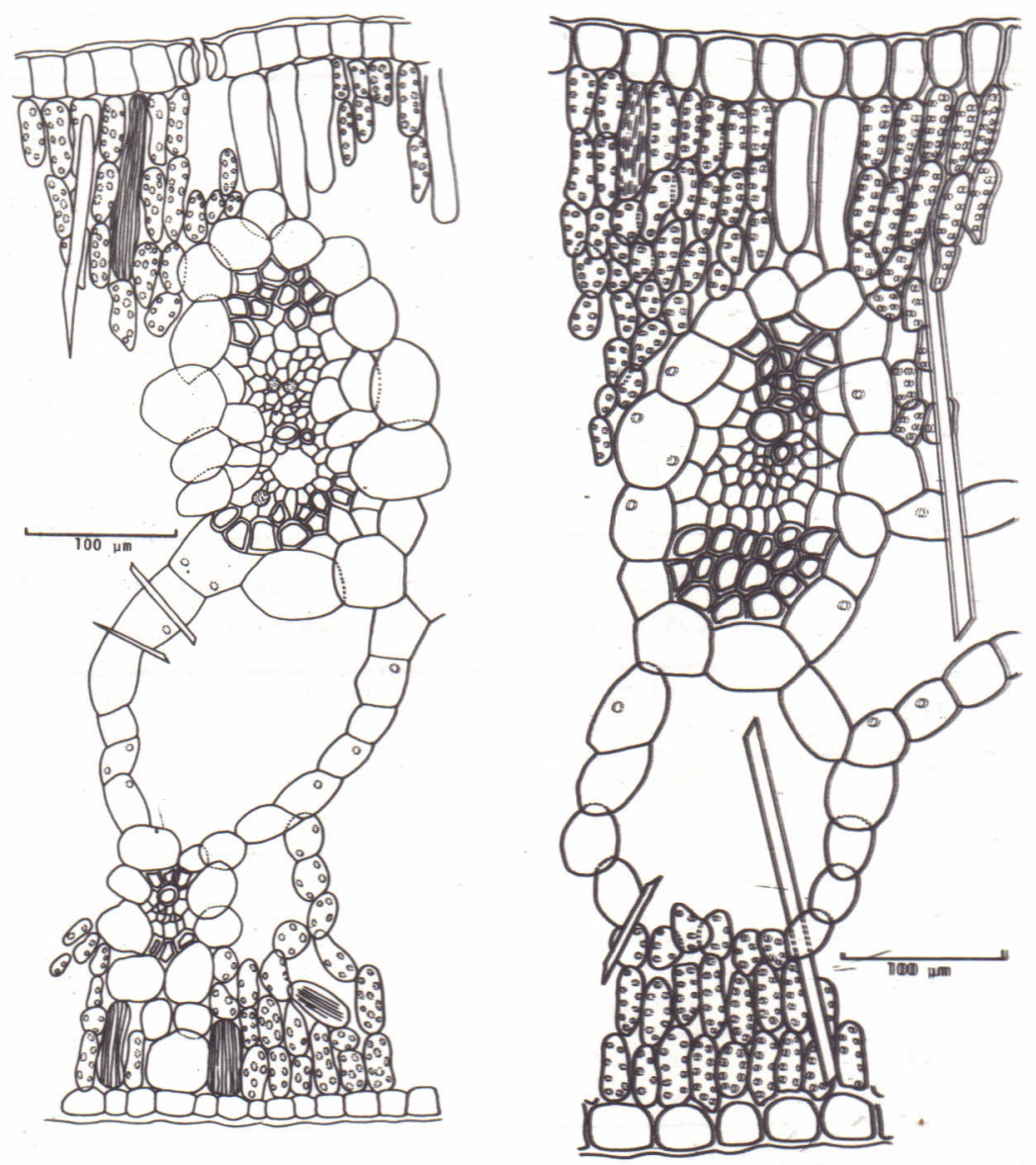

Figura 1. Corte transversal da lâ mina da folha de pecio 10 longo.

Figura 2. Corte transwersall dia lâmina da follha dile cỉolo inflado.

Epiderme

A epiderme das faces adaxial e abaxial da lámina das fo lhas de peciolo longo e inflado apresenta-se simples, constituindla por células aproximadamente isodiamétricas, de contorno poligonal. As pa redes periclinais externas das células epidérmicas são revestidias por cutícula fina. 


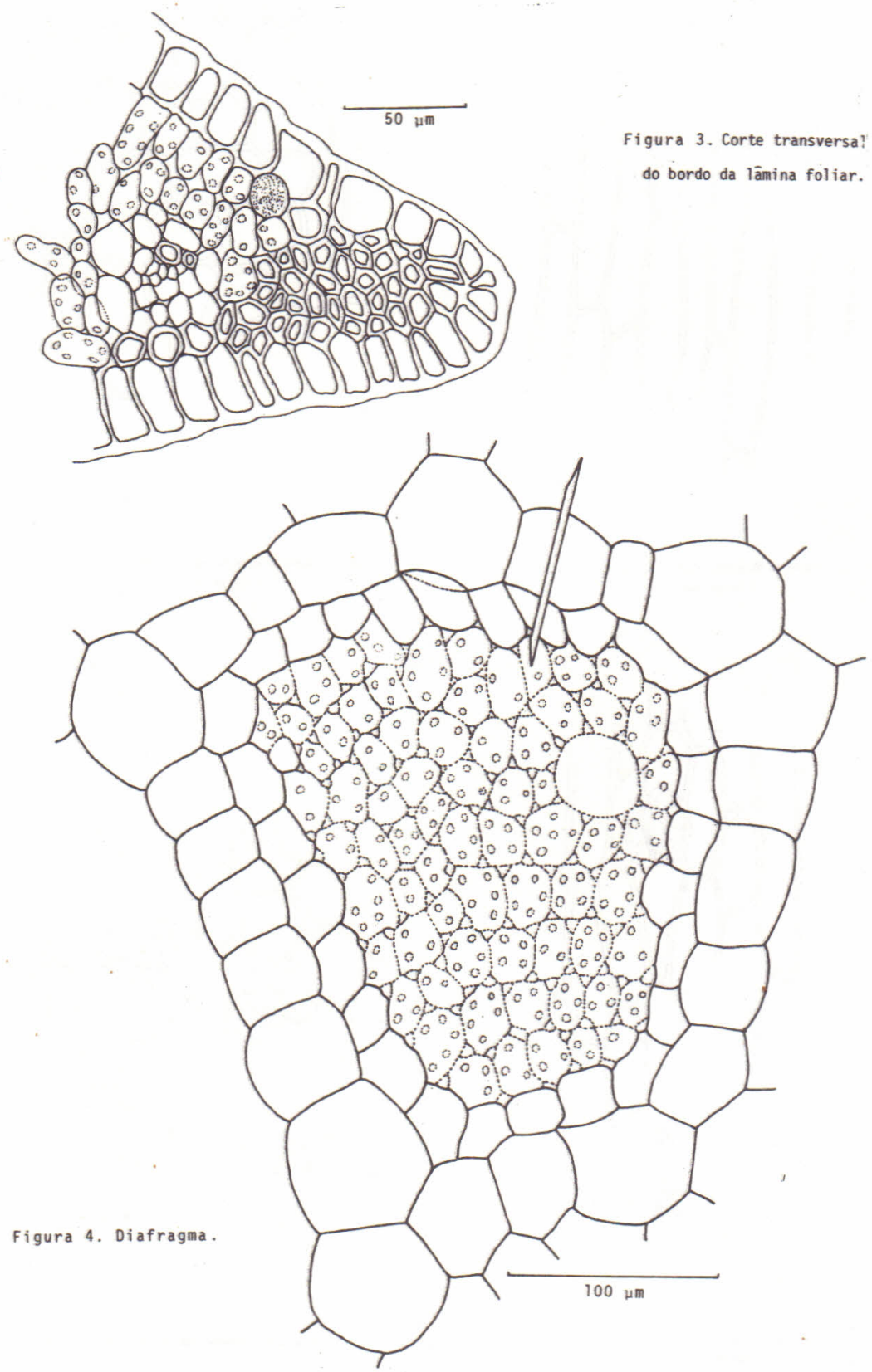




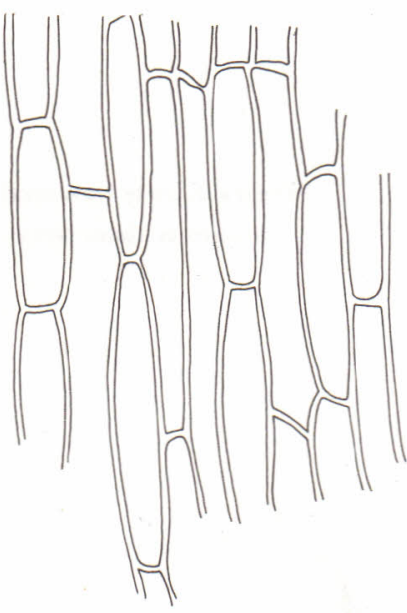
Figura 5. Epiderme abaxial, do peciolo longo,
vista de face.

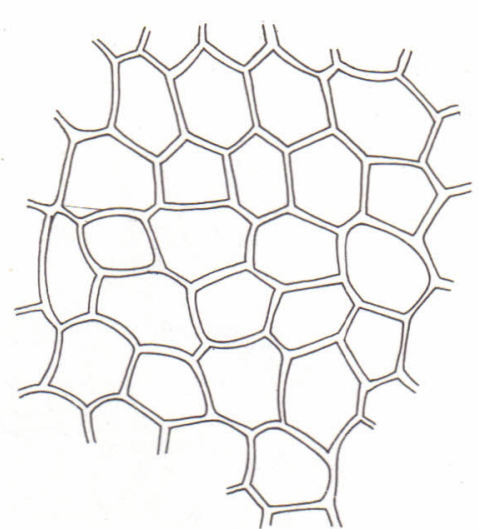

Figura 7. Epiderme abaxial, do peciolo inflado, vista de face.
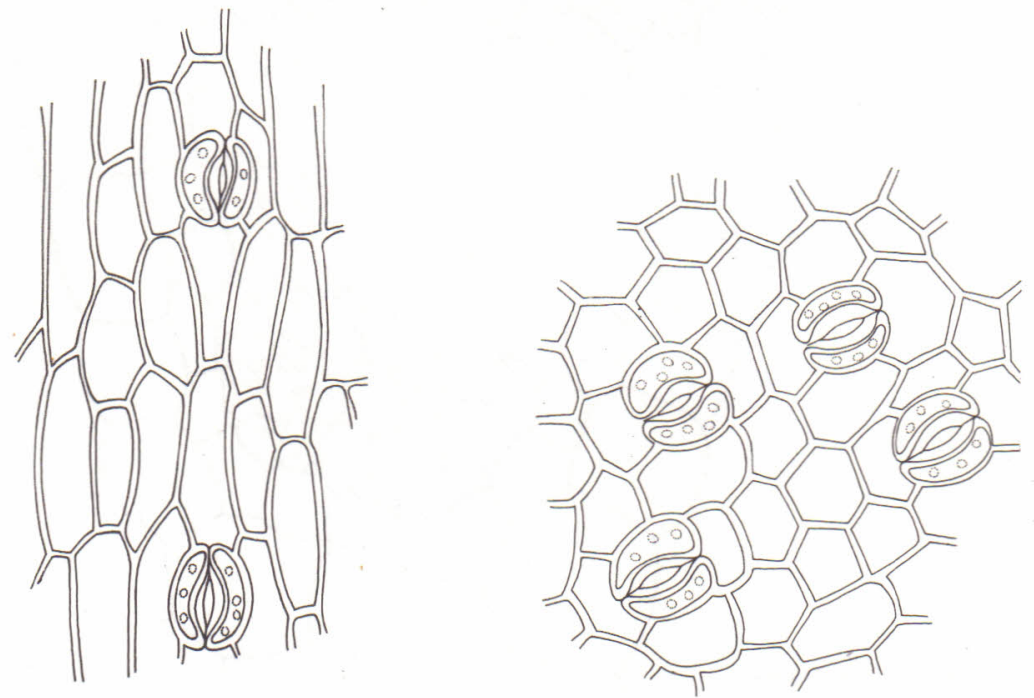

Figura 6. Epiderne adaxial, do peciolo longo, vista de face.

Figura 8. Epideme adaxial, do peciolo inflado, vista de face. 


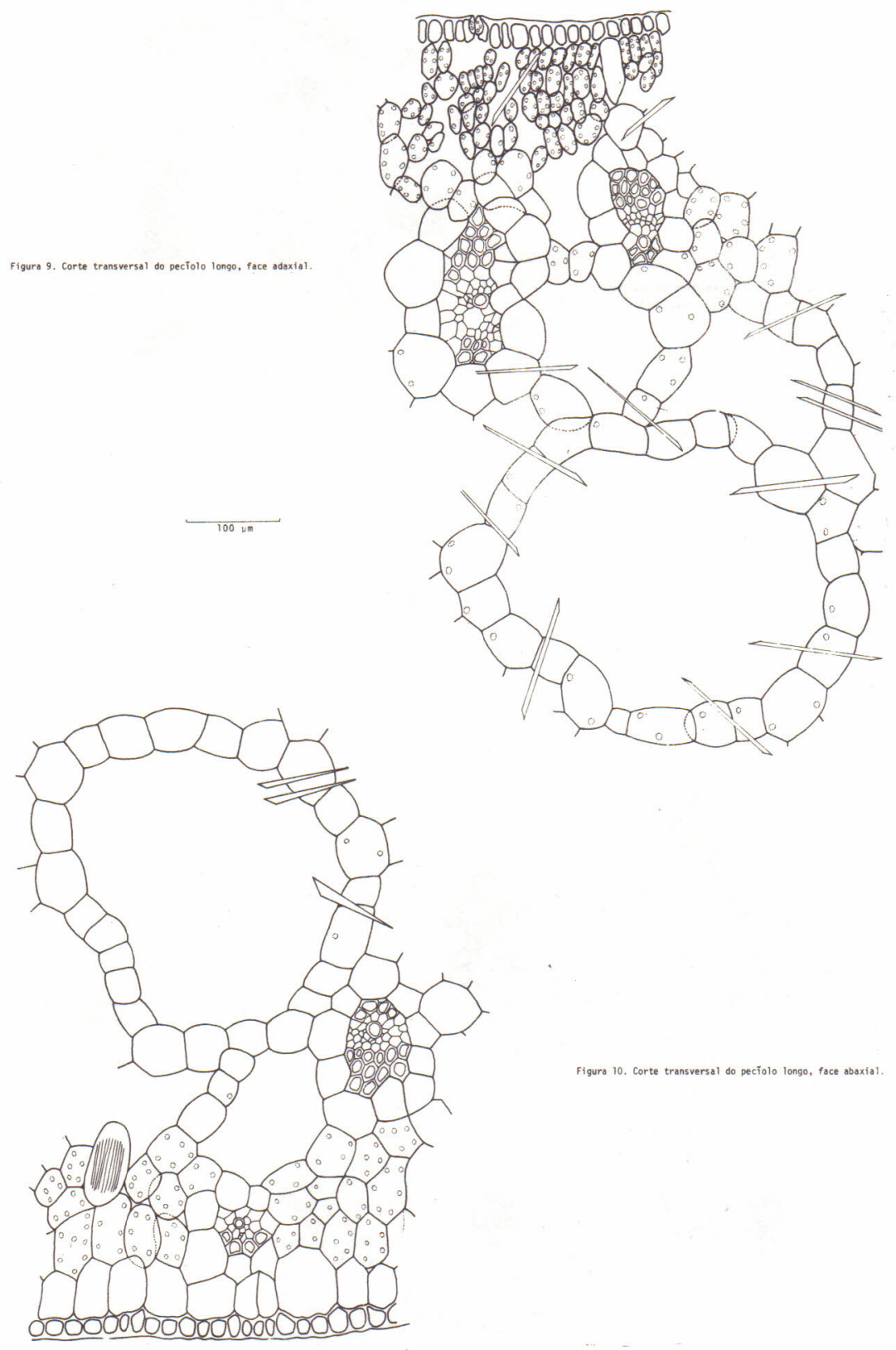



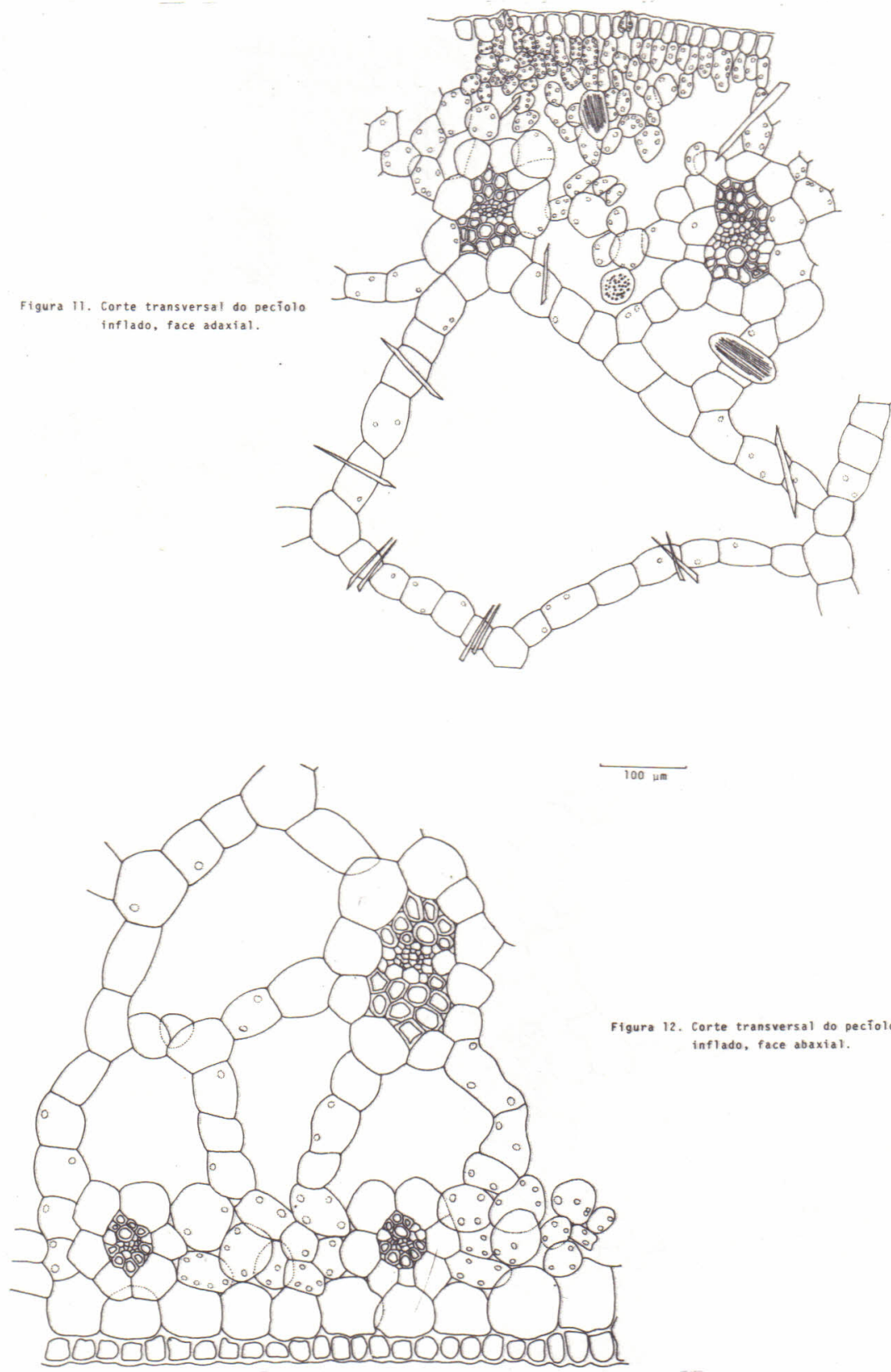

fgura 12. Corte transversal do peciolo inflado, face abaxial. 
Estômatos

Os estômatos estão presentes na face adaxial e são raros na face abaxial da lâmina das folhas de peciolo longo. Na lâmina das folhas de peciolo inflado, os estômatos estão presentes na face ada xial e ausentes na face abaxial.

Mesófizo

Em ambas as folhas, com peciolo longo e peciolo inflado,o mesōfilo está diferenciado em parēnquima paliçādico e aerēnquima(F guras 1 e 2). 0 parénquima paliçádico ocorre nas duas faces da lâmi na. Na folha de peciolo longo, até 10 camadas de cēlulas de parénqui ma paliçādico são observadas na face adaxial e até 4 na face abaxial da lâmina. Na foltha de pecīolo inflado, ocorrem até 6 camadas de cé lulas de parênquima paliçādico na face adaxial e até 3 na face aba $x$ ia 1 .

0 aerênquima localiza-se entre os parênquimas paliçädico adaxial e abaxial. Na folha de peciolo longo cerca de $83,5 \%$ do volu me do aerénquima é ocupado por células e $16,5 \%$ por espaços aeríferos, enquanto que na folha de peciolo inflado, $68,1 \%$ do volume do aerénqui ma é ocupado por células e $31,9 \%$ por espaços aeriferos (Tabela I).

Entre as células clorofiladas do parénquima paliçádico o correm cēlulas alongadas anticlinalmente que apresentam conteūdo mu cilaginoso. Idioblastos cantendo räfides e estilóides com até 80 mi crómetros de comprimento, são observados no parénquima paliçádico e no aerénquima (Figura 1 ).

Feixes vasculares

Cortes transversais da lämina mostram os feixes vasculares distribuidos predominantemente em duas camadas alternando-se, irregu larmente, feixes maiores e menores. Os feixes vasculares são colate rais e acham-se envolvidos por uma bainha parenquimática que alcan ça uma das epidermes (Figura 2). Externamente ao xilema e floema são observadas fibras.

o xilema é constituido por um ou dois vasos, sendo que nos feixes vasculares mais velhos os primeiros elementos formados estão destruidos e no seu lugar existe uma lacuna (Figura 2).

0 floema é composto de poucos elementos.

Nos bordos da lâmina, o nümero de células de parénquima paliçādico vai diminuindo gradativamente até que estas sejam total mente substituidas por fibras (Figura 3 ). Nesta região a epiderme é formada por células menores.

ESTRUTURA DO PECIOLO

Alguns aspectos da estrutura do peciolo longo e inflado, ao nivel da região mediana, são descritos a seguir (Figuras 4 a 12). 
Epiderme

A epiderme é simples e está revestida de cutîcula fina. As células epidérmicas do pecỉolo longo são retangulares quando vistas de face (Figuras 5 e 6). Seu maior diâmetro é paralelo ao eixo maior do örgão. As cēlulas epidērmicas do pecíolo inflado são quadrangula res quando vistas de face (Figuras 7 e 8 ). A face adaxial de ambos os peciolos possui estómatos (Figuras 6 e 8 ). A face abaxial não pos sui estômatos ou estes são raros. As cēlulas oclusivas estão local zadas pouco acima das demais cēlulas epidérmicas.

Parênquima

Na face adaxial, apōs a epiderme, ocorre parénquima cloro filiano, nos peciolos longos e inflados (Figuras 9 e 11). Observa-se um número maior de camadas celulares no pecỉolo longo. Na face aba xial de ambos os pecỉolos, ocorre uma camada de células parenquimá ticas, grandes e incolores (Figuras 10 e 12). Em posição mediana, está o aerēnquima (Figuras 9 e 12). Este ocupa a maior parte da es trutura do pecíolo. No pecíolo longo, cerca de $45,4 \%$ do volume do aerēnquima é ocupado por cēlulas e $54,6 \%$ por espaços aeríferos, en quanto que no pecĩolo inflado, as cēlulas ocupam um volume de $21 \%$ e os espaços aerîferos 79\% (Tabela II). As cavidades do aerēnquima são limitadas transversalmente por uma membrana diafragma, formada. de uma só camada de cēlulas, ricas em cioroplastos (Figura 4). Tantono parênquima clorofiliano como no aerēnquima, encontram-se idioblastos com rāfides e estilōides muito longos. Estes cristais são mais nume rosos no aerênquima (Figura 9).

Feixes vasculares

Os feixes vasculares, sempre envoltos por bainha parenqui mática, encontram-se dispersos através do corte. Os primeiros feixes vasculares são pequenos e estão inclusos no parénquima clorofiliano. A medida que os feixes vasculares se distanciam da periferia do ōr gão, apresentam-se maiores (Figuras 9 e 12). Na região do aerênqui ma, cada feixe vascular é circundado por seis espaços aerīferos. Es tes espaços, através de suas células circundantes, se conectam com os espaços aeríferos que rodeiam outros feixes vasculares formando, assim, uma verdadeira rede. Xilema e floema, como è comum ocorrer nas plantas aquáticas, possuem poucos elementos, sendo que aparecem la cunas no lugar dos vasos de xilema mais velhos. Externamente ao xile ma e floema são observadas fibras.

CONCLUSOES

Com base na anatomia comparada de folhas de Eichhornia crassipes, concluiu-se que: 
A forma, dimensões e estrutura do peciolo alteram-se em função do ambiente.

As folhas de peciolo longo e inflado diferem estrutural mente quanto ao volume de espaços aeríferos do aerénquima.

o substrato, a ārea superficial disponível ao crescimento e provavelmente a luz, são fatores ambientais que contribuem para a variação morfolōgica das folhas.

\section{AGRADECIMENTOS}

Aos professores Dra. Maria Helena Achutti e José Newton Mar chiori, pelas sugestões e eficaz cooperação durante a realização des te trabalho.

\section{BIBLIOGRAFIA CITADA}

1. CASTELLANOS,A. \& KLEIN,R. Pontederiáceas. Flora IZustrada Catari nense. Itajaî, Santa Catarina. 1967. 17p.

2. ESAU, K. Anatomy of seed plants. 2 ed. New York, John Wiley \& Sons. $1977.550 \mathrm{p}$.

3. HOEHNE,F.C. Plantas aquáticas. São Paulo, Instituto de Botânica, Série "D". 1955. $168 \mathrm{p}$.

4. IFJU,G. Quantitative wood anatomy - a stereological approach. Blacks burg, VPI: IPT. 1977. 26 p.

5. JENSEN,W.A. Botanical histochemistry: principles and practice.San Francisco, W. H. Freeman. 1962. 408 p.

6. JOHANSEN,D.A. Plant microtechnique. New York, Mac Graw - Hill Book Comp. 1940. $523 \mathrm{p}$.

7. MORRETES,B.L. Contribuigão ao estudo da anatomia das folhas de plantas do cerrado II. Bolm. Filos. Ciēnc. Univ. São Paulo 305 (BOT) 22: 207-244. 1976.

8. SASS,J.E. Botanical microtechnique. 2 ed. Iowwa, The Iowa State College. 1951. $228 \mathrm{p}$.

9. WEAVER \& CLEMENTS. Ecologia Vegetal. Trad. Angel L. Cabrera Acme Agency, Soc. Resp. Ltda. Buenos Aires. 1944. 667 p.

Recebido em outubro, 1980; aceito em outubro, 1980. 
